\section{Blood-wall interaction}

Prof. K. Affeld, Universitätsklinikum Rudolf Virchow, Spandauer Damm 130, D-1000 Berlin 19, Germany

18-21 October 1993, Berlin, Germany

312. Turbulence and vortices in hypersonic flows

Dr F.-R. Grosche, DLR Institute for Experimental Fluid Mechanics, Bunsenstraße 10, D-3400

Göttingen, Germany

5-7 October 1993, Göttingen, Germany

313. CFD in turbomachinery and experimental validation Prof. J. L. Kueny, CREMHyG, BP 95, F-38402

Saint Martin d'Hères, France

Prof. F. Leboeuf, Ecully

9-10 December 1993, Val d'Isére (Rhones Alpes),

France

314. Effectiveness of shell-theory formulations for numerical solutions

Prof. E. L. Axelrad, Universität der Bundeswehr

München, W.-Heisenberg-Weg 39, D-8014

Neubiberg, Germany

Prof. F. A. Emmerling, Neubiberg

14-18 September 1993, Munich-Neubiberg,

Germany

\section{Euromech Conferences}

are broad in scientific scope. They are open to all those interested and are expected to have a number of participants between 150 and 600 . The general purpose is to provide opportunities for scientists and engineers from all parts of Europe to meet and discuss current research. The responsibility for each series of Conferences is delegated to a Standing Committee. The detailed organizational work is carried out by Local Organizing Committees (LOC). Those who are interested in taking part in one of the Conferences should write to the Chairman or Secretary of the appropriate LOC. Some information about the Euromech Conferences in 1993 and 1994 is given below.

\section{1st European Nonlinear Oscillations Conference}

Prof. E. Kreuzer, Meerestechnik II, Technische Universität Hamburg-Harburg, Eißendorfer Straße 42, D-2100 Hamburg 90, Germany 16-20 August 1993, Hamburg, Germany

5 th European Turbulence Conference

Prof. R. Benzi, Rome

Summer 1994, Italy

2nd European Solid Mechanics Conference

Prof. A. del Grosso, Istituto di Scienza delle Costruzioni, Università di Genova, Via Montallegro 1, I-16145 Genova, Italy

12-16 Septcmber 1994, Genoa, Italy

2nd European Fluid Mechanics Conference

Prof. H. Zorski, Institute of Fundamental Technological Research, Polish Academy of Sciences, Swietokrzyska 21, 00-049 Warsaw, Poland, and

Prof. J. S. Ostrowski, Institute of Aeronautics and Applied Mechanics, Warsaw University of Technology, Nowowiejska 22/24, 00-665 Warsaw, Poland

19-23 September 1994, Cracow, Poland

Errata to the paper by A. Linkov and N. Filippov, 'Difference equations approach to the analysis of layered systems' (Meccanica 26 (1991), 195-209).

The expressions for $v_{*}^{i}$ on page 202 are incorrect. The right expressions are

$$
\begin{array}{ll}
v_{*}^{i}=2 v^{i} /\left(1+v^{i}\right) & \text { under plane stress conditions; } \\
v_{*}^{i}=2 v^{i} & \text { under plane strain conditions. }
\end{array}
$$

The authors regret any inconvenience caused by these unfortunate errors. 